\title{
BIOINSPIRED MAGNETO-OPTICAL BACTERIA
}

Fernando Carmona, Miguel Martín, Natividad Gálvez, Jose M. Dominguez-Vera

\begin{abstract}
Two-in-one" magneto-optical bacteria have been produced using the probiotic Lactobacillus fermentum ${ }^{\circledR}$ for the first time. We took advantage of two features of bacteria to synthesize this novel and bifunctional nanostructure: their metal-reducing properties, to produce gold nanoparticles, and their capacity to incorporate maghemite nanoparticles at their external surface. The magnetooptical bacteria survive the process and behave as magnets at room temperature.
\end{abstract}

Keywords: Magnetic Nanoparticles, Gold Nanoparticles, Bioinspired Materials.

Tremendous interest in the possibility of using bifunctional gold-magnetite nanomaterials for biomedical and electronic applications has led to increased research into the synthesis of such materials. ${ }^{1-8}$ Synthetic methods usually involve the use of toxic chemicals, high temperatures and pressures, and result in particles that become unstable or aggregate upon interaction with biological media. An alternative approach to traditional synthetic chemistry is the biosynthesis of nanomaterials which employs natural organisms that reduce metal ions into stable nanoparticles. ${ }^{9-16}$ Moreover, it should be borne in mind that there is ever increasing pressure to develop green, eco-friendly and economically-viable synthetic routes to nanomaterials. This has resulted in researchers turning towards biological organisms for inspiration.

Microorganisms, such as bacteria and fungi, can be successfully used for large scale production of small particles at an extracellular level.9-16 Biosynthesized nanoparticles usually exhibit enhanced stability and afford better control over morphology. Furthermore, bio-based fabrication has been shown to be reproducible and includes the possibility of synthesizing hydrophilic nanoparticles. ${ }^{17}$

Despite these advantages, the use of microorganisms as potential nanoparticle biofactories is a relatively new area of research. Most of the known examples 
deal with the synthesis of microbial mediated zero-valent metal nanoparticles, especially gold. Gold nanoparticles are in fact formed by a variety of metalreducing microorganisms. Although the mechanism has not yet been fully elucidated, it is roughly assumed that the biofilm would capture Au(III) ions on its external surface. The Au(III) ions are then thought to be reduced by biomolecules secreted by the bacteria producing $\mathrm{Au}$ atoms that would aggregate at specific sites to form nanoparticles. ${ }^{9}$

On the other hand, other bacteria are capable of adsorbing, at extracellular level, amorphous magnetite nanoparticles by a biologically induced process, of which the mechanism is still unknown. Similarly, we have recently reported that the direct adhesion of magnetic nanoparticles onto the biofilm of some bacteria is also a viable route for producing novel magnetic bacteria. ${ }^{22}$

Inspired by the existence of both metal-reducing microorganisms capable of producing extracellular gold nanoparticles from the metal cations and microorganisms that can capture iron oxide nanoparticles at an extracellular level, we have designed a new route that incorporates both processes. In this work we describe the preparation of a new type of "two-in-one" magneto-optical bacteria based on maghemite and gold nanoparticles.

The presence of both magnetic and gold nanoparticles in a single nanostructure is a powerful way to combine the properties of two of the most interesting metallic nano-building blocks. On the one hand, magnetic nanoparticles are of paramount importance in biomedicine as diagnostic tools in magnetic resonance imaging, as mediators for hyperthermic cancer treatment, and as drug-delivery vehicles. ${ }^{23-26}$ On the other hand, gold nanoparticles are being employed in biomedicine because of their unique optical, electrical and photothermal properties. ${ }^{27-30}$ In this context, in recent years, a wide range of gold-magnetic nanoparticles have been developed by a variety of physical, chemical and biological methods, most of them, leading to core-shell Au-magnetite nanoparticles. ${ }^{31-35}$

Here we show that bacteria such as Lactobacillus fermentum ${ }^{\circledR}$, known to have a positive effect on the maintenance of human health since they constitute an important part of natural microbiota, can reduce $\mathrm{Au}(\mathrm{III})$ ions to produce discrete extracellular gold nanoparticles and then, in a second step, are able to 
incorporate maghemite nanoparticles, also at the external surface, therefore producing bifunctional magneto-optical bacteria. As far as we know, this is the first example of a microorganism simultaneously containing optical gold and magnetic maghemite nanoparticles.

Furthermore, toxicity assessments showed that neither the gold nor the maghemite particles were especially toxic or inhibitory to these bacteria. Thus, using this hybrid natural-synthetic approach, we succeeded in obtaining living bacteria that behave as magnets at room temperature and exhibit optical properties. We found that when an aqueous $\mathrm{Au}(\mathrm{III})$ solution was added to a culture of Lactobacillus fermentum ${ }^{\circledR}$, the reaction mixture turned from pale yellow to red within $30 \mathrm{~min}$, indicating the formation of gold nanoparticles (Figure 1). The UV-visible absorption spectrum recorded from the gold- loaded bacteria exhibited a surface plasmon band at $520 \mathrm{~nm}$, which is characteristic of $\mathrm{Au}$ nanoparticles, that was not observed for the supernatant after bacteria centrifugation.

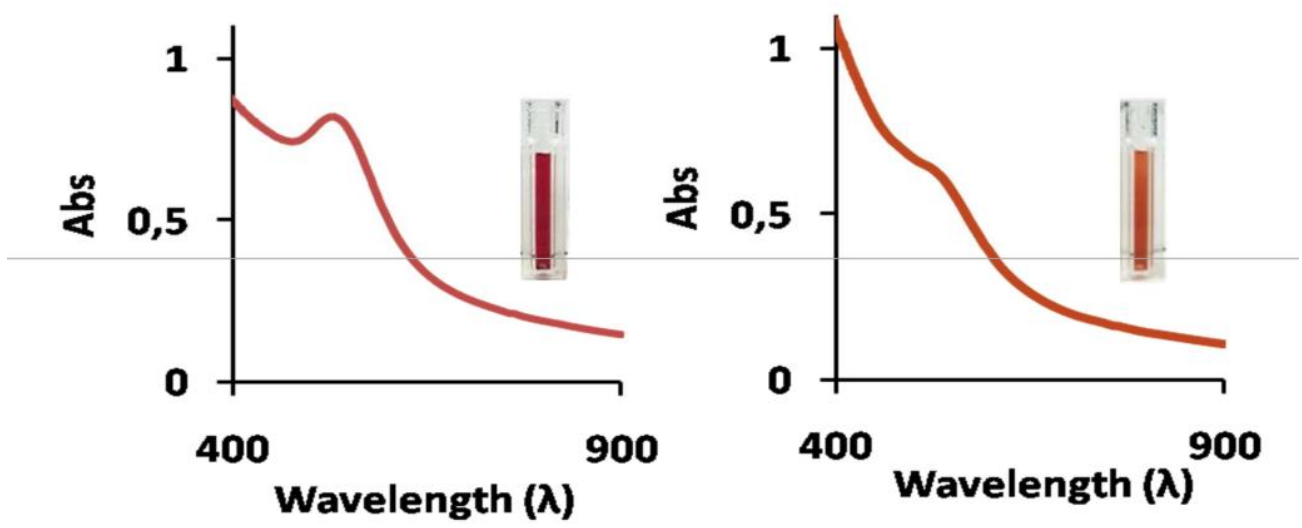

Figure 1. UV-Vis spectra of just gold and gold+maghemite-labelled Lactobacillus fermentum ${ }^{\circledR}$.

To gain further insight into the role of Lactobacillus fermentum ${ }^{\circledR}$ in gold nucleation, we chemically reduced Au(III) in the absence of the bacteria, but in the presence of the extracellular reductant solution generated by the cultivated 
bacteria. For this purpose, Lactobacillus fermentum ${ }^{\circledR}$ were cultivated, centrifuged and the supernatant solution isolated. Interestingly, when an aqueous Au(III) solution was added to the supernatant extracted from the Lactobacillus fermentum ${ }^{\circledR}$ culture, the reaction mixture changed from pale yellow to produce different colors within $1 \mathrm{~h}$ and finally formed a black precipitate, indicating the formation of gold aggregates. Based on these observations, it can be deduced that gold particles are likely produced with the aid of bacterial extracellular reducing agents. In parallel, they also suggest the existence of a chemical site of gold nucleation on the external bacterial surface. This would explain the stability of the gold nanoparticles once incorporated onto the bacteria and also the absence of any size (or color) evolution with time. Purification and physicochemical characterization of the biomolecules involved in the microbial synthesis of gold nanoparticles need to be investigated. Further analytical and proteomic studies are currently being conducted in order to attain a thorough understanding of the mechanism and nature of the reducing agent(s) and the nucleation site.

Having isolated the gold nanoparticle-loaded bacteria, they can serve as precursors for the incorporation of maghemite nanoparticles, thus incorporating magnetic properties to thereby obtain the first magneto-optical microorganisms. A liquid culture of gold-Lactobacillus fermentum ${ }^{\circledR}$ was incubated with an acidic solution of maghemite nanoparticles. ${ }^{36}$ The resulting bacteria, labeled with gold and maghemite nanoparticles, were collected by centrifugation then dispersed in water to form a reddish-brown solution. This solution was examined by UV-Vis spectroscopy and Transmission Electron Microscopy (TEM). As shown in Figure 1 , the surface plasmon resonance remains at the same wavelength, which confirms that gold nanoparticles remain intact after the incorporation of the maghemite ones. In fact, the supernatant liquid after the final isolation of the magneto-optical bacteria did not contain any gold. 


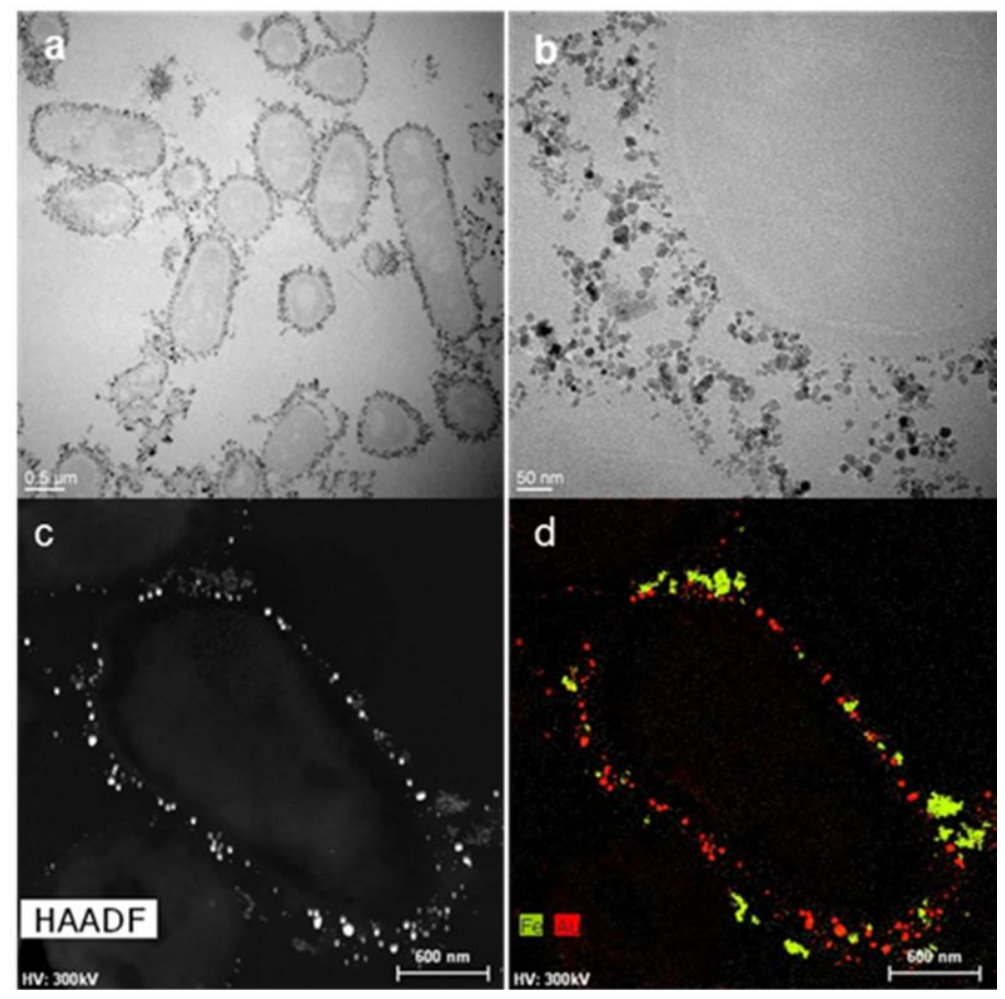

Figure 2. a) TEM micrograph of a thin epoxy resin section showing the presence of particles at the external surface of the gold+maghemite-labeled bacteria. b) An area of (a) at higher magnification, showing the different contrast of gold and iron-containing nanoparticles. c) HAADF-STEM micrograph of a single bacterium. d) EDX compositional maps of iron (green) and gold (red) collected over the whole $H A A D F-S T E M$ image in (c).

Large accumulations of nanoparticles on the external bacterial surface were revealed by TEM (Figures $2 \mathrm{a}$ and $2 \mathrm{~b}$ ). Gold and maghemite nanoparticles are attached to each bacterium, as demonstrated by high-angle annular dark field scanning transmission electron microscopy (HAADF-STEM) (Figure 2c) and energy-dispersive X-ray spectroscopy (EDX) (Figure 2d). However, maghemite nanoparticles (in green, Figure 2d) tend to form aggregates while gold nanoparticles are well dispersed throughout the bacteria surface. The intensity of the HAADF-STEM images depends primarily on the atomic number (Z) and thickness of the specimen. A typical HAADF image of the gold+maghemite-labeled bacteria (Figure 2c) shows clear evidence of a different contrast between gold and 
iron-containing nanoparticles, which serves to distinguish between the two kinds of particles. Every bacterium contains less-bright particles, corresponding to iron oxide structures with a lower $\mathrm{Z}$, and brighter particles, corresponding to the gold nano-blocks. The presence of both gold and maghemite nanoparticles on each bacterium was unequivocally confirmed when inspected by EDX Au and Fe mapping, as can be seen in Figure 2d. Both gold and maghemite particles had relatively homogeneous size distributions and were approximately spherical. The gold nanoparticles produced were in the size range of $3-18 \mathrm{~nm}$, with an average of $7 \pm 2 \mathrm{~nm}$ whereas the maghemite particles were centered around $10 \mathrm{~nm}$.

Figures $3 \mathrm{a}$ and $3 \mathrm{~b}$ show typical HREM images of agglomerates of maghemite and gold nanoparticles, respectively, surrounding the bacterial wall. Under high resolution HREM the lattice fringes of both nanoparticles can be observed, thus confirming their crystalline nature. Measured d-spacing and electron diffraction patterns were indexed according to the maghemite and gold structures (Figures $3 \mathrm{c}$ and $3 \mathrm{~d}$, respectively). 


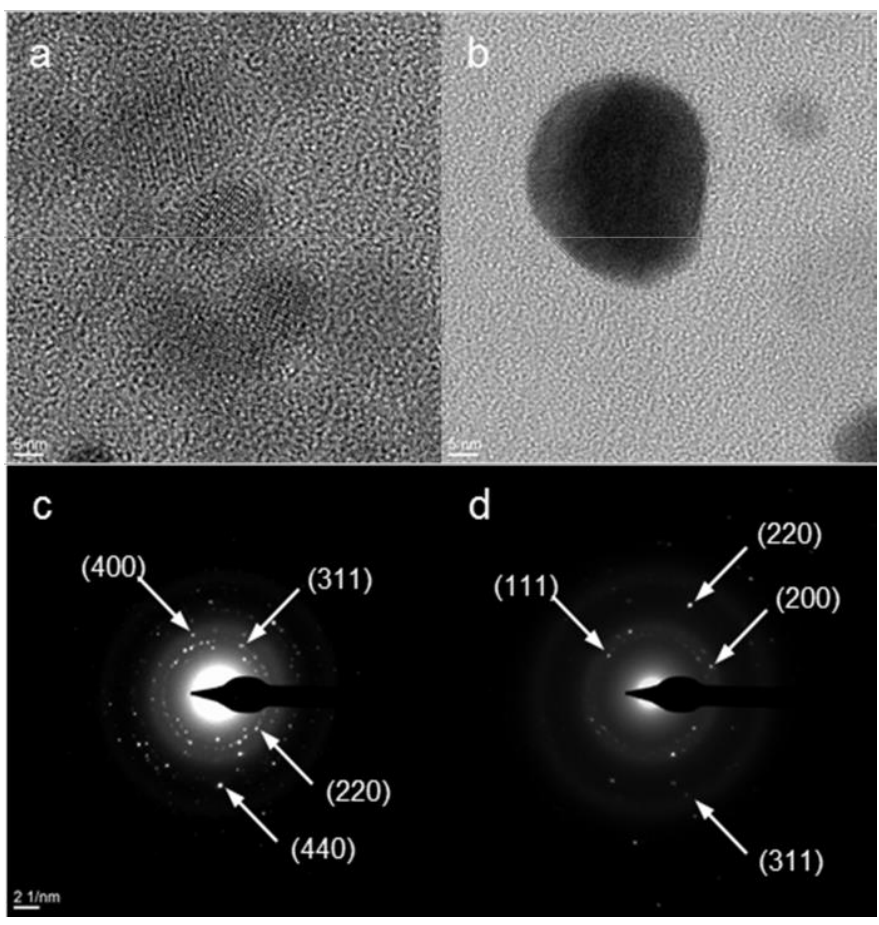

Figure 3. a) HREM micrograph of maghemite nanoparticles. b) HREM micrograph of a single gold nanoparticle. c) Electron diffraction pattern of maghemite particles of (a) with labeled reflexions. d). Electron diffraction pattern of the gold particle of (b) with labeled reflexions.

Figure 4 provides clear evidence that the magneto-optical gold+maghemiteLactobacillus fermentum ${ }^{\circledR}$ bacteria have ferromagnetic properties at room temperature as they transfer across a liquid medium placed in the magnetic field of an external magnet. Note that the area of the liquid medium furthest from the magnetic field source is almost colorless, this underlines the fact that both maghemite and gold nanoparticles are collectively associated in the same bacterial platform. Magnetic studies of lyophilized gold+maghemite-Lactobacillus fermentum ${ }^{\circledR}$ samples were performed using a superconducting quantum interference device (SQUID). Hysteresis loop with coercivity (10 0e) is observed at $300 \mathrm{~K}$, indicating a permanent magnetism even at room temperature. The magnetization vs. H curve at room temperature showed a sharp increase, reaching saturation at low fields (Figure 4). These results are indicative of a collective ferromagnetic phase at room temperature. This behavior is also apparent from the 
temperature dependence of the field-cooled (FC) and zero-field-cooled (ZFC) magnetization. The data presented a maximum in the ZFC curve at $130 \mathrm{~K}$, which is generally ascribed to the average blocking temperature of the magnetic moment.

Magnetization decreases slightly with increasing temperature but nonetheless shows permanent magnetization at room temperature.
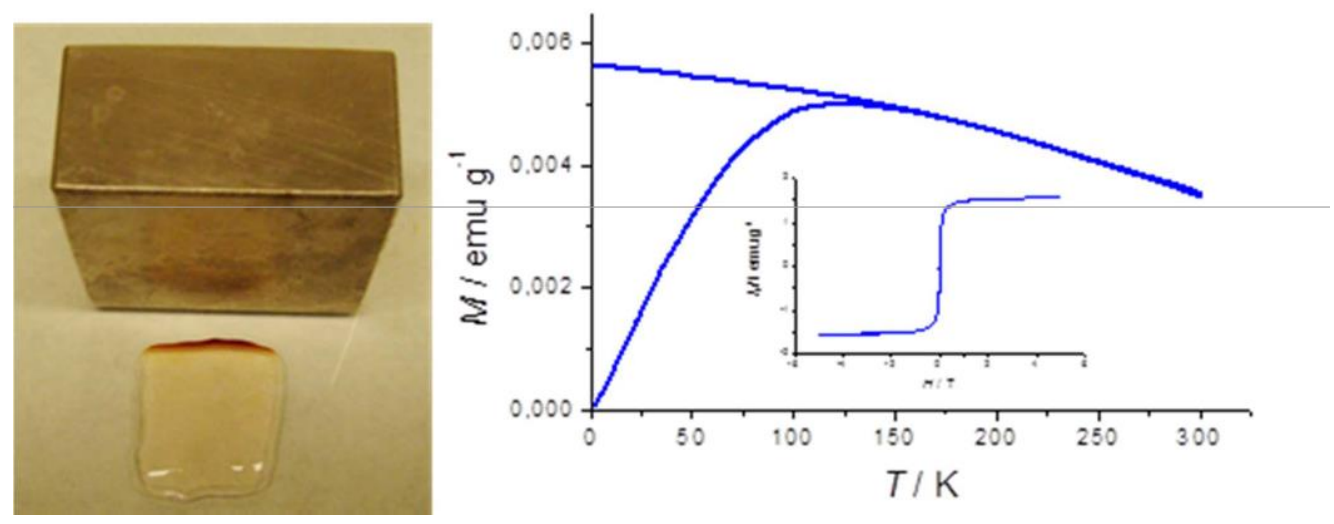

Figure 4. Field-cooled (FC) and zero-field-cooled (ZFC) curves of lyophilized gold+maghemite- Lactobacillus fermentum ${ }^{\circledR}$ powder. Inset: hysteresis curves at 300 $K$ of lyophilized gold+maghemite-Lactobacillus fermentum ${ }^{\circledR}$ powder. Photo: Application of a magnetic field to an aqueous dispersion of gold+maghemiteLactobacillus fermentum ${ }^{\circledR}$ produced attraction of the magneto-optical bacteria

It must be emphasized that isolated maghemite nanoparticles of this size range $(10 \mathrm{~nm})$ are superparamagnetic at room temperature and do not show persistent magnetization. ${ }^{38-39}$

However, once they are incorporated into the external bacterial surface, dipoledipole interactions occur due to the close mutual proximity of the maghemite particles so that the maghemite-gold bacteria behave as ferromagnets at room temperature. This behavior is consistent with results that we have reported previously, in which massive incorporation of maghemite nanoparticles onto the bacteria surface yielded increased magnetic properties. ${ }^{22}$ 
Additionally, assessment of the antibacterial activity of these particles revealed that they are non-toxic and nor do they significantly inhibit this kind of bacteria. $^{38}$ Quantification of bacterial proliferation was performed using Live/Dead Bacterial Viability Kits SYT09 (green) and propidium iodine (red), by counting the number of live (green) and dead (red) bacteria. The average live/dead ratio was used to quantify the effect of gold and maghemite nanoparticles upon bacterial proliferation by comparing with control cultures in the absence of nanoparticles. The presence of nanoparticles resulted in a slight decrease of the live/dead ratio of $15-25 \%$ with respect to control experiments. ${ }^{40}$

As conclusions, it must first emphasize that the putative potential of probiotic bacteria for the biosynthesis of metal nanoparticles is still a relatively unexplored field. Here we describe the first demonstration of the bio-fabrication of discrete gold nanoparticles using the metal-reducing Lactobacillus fermentum ${ }^{\circledR}$ bacterial strain. The resulting gold-loaded bacteria can be used, in a second step, as a precursor for the incorporation of maghemite nanoparticles, thus producing for the first time living bacteria that behave as magnets at room temperature and which also exhibit optical properties.

The biosynthesized magneto-optical nanoparticles built around these kinds of organisms may benefit from their large-scale production, and perhaps of their implementation for various biomedical applications through its inclusion in food, where probiotic bacteria are incorporated since they confer health benefits for men.

\section{Notes and references}

(1) Quaresma, P.; Osorio, I.; Doria, G.; Carvalho, P. A.; Pereira, A.; Langer, J.; Araujo, J. P.; Pastoriza-Santos, I.; Liz-Marzan, L. M.; Franco, R. RSC Advances. 2014, 4, 36593667.

(2) Umut, E.; Pineider, F.; Arosio, P.; Sangregorio, C.; Corti, M.; Tabak, F.; Lascialfari, A.; Ghigna, P. J. Mag. and Mag. Mater. 2012, 324, 2373-2379. 
(3) Sheng, Y.; Xue, J. J. of Colloid and Interf. Sci. 2012, 374, 96-101. (4) Bhattacharya, D.; Chakraborty, S. P.; Pramanik, A.; Baksi, A.; Roy, S.; Maiti, T. K.; Ghosh, S. K.; Pramanik, P. J. Mater. Chem. 2011, 21, 17273.

(5) Yu, H.; Chen, M.; Rice, P. M.; Wang, S. X.; White, R. L.; Sun, S. Nano Lett. 2005, 5, 379.

(6) Jain, P. K.; El-Sayed, I. H.; El-Sayed, M. A. Nanotoday. 2007, 2, 18.

(7) Salgueiriño-Maceira,V.; Correa-Duarte, M. A.; Lopez- Quintela, M. A.; Rivas, J. J. of Nanosci. and Nanotech. 2009, 9, 3684- 3688.

(8) Salgueiriño-Maceira, V.; Correa-Duarte, M. A.; Lopez-Quintela,M.A.;Rivas, J. Sensor Letters. 2007, 5, 113-117.

(9) Suresh, A. K.; Pelletier, D. A.; Wang, W.; Broich, M. L.; Moon, J. W.; Gu, B.; Allison, D. P.; Joy, D. C.; Phelps, T. J.; Doktycz, M. J. Acta Biomaterialia. 2011, 7, 2148-2152.

(10) Bhambure, R.; Bul, M.; Shaligram, N.; Kamat, M.; Singhal, R. Chem. Eng. Technol. 2009, 32,1036-41.

(11) Mukherjee, P.; Senapati, S.; Mandal, D.; Ahmad, A.; Khan, M. I.; Kumar, R.; Sastry, M. Chembiochem. 2002, 3, 461-463.

(12) Mukherjee, P.; Ahmad, A.; Mandal, D.; Senapati, S.; Sainkar, S. R.; Khan, M. I.; Ramani, R.; Parischa, R.; Ajayakumar, P. V.; Alam, M.; Sastry, M.; Kumar, R. Angew. Chem. Int. Ed. 2001, 40, 3585-3588.

(13) Ahmad, A.; Senapati, S.; Khan, M. I.; Kumar, R.; Sastry, M. Langmuir. 2003, 19, 3550-3553.

(14) Das, S. K.; Das, A. R.; Guha, A. K. Langmuir. 2009, 25, 8192- 8109.

(15) Ramanathan, R.; Field, M. R.; O'Mullane, A. P.; Smooker, P. M.; Bhargava, S. K.; Bansal, V. Nanoscale. 2013, 5, 2300-2306.

(16) Inbakandana, D.; Venkatesan, R.; Khan, S. A. Colloids and Surfaces B: Biointerfaces. 2010, 81, 634-639.

(17) Bansal, V.; Bharde, A.; Ramanathan, R.; Bhargava, S. K. Adv. In Colloid and Interf. Sci. 2012, 179-182, 150-168. 
(18) Roh, Y.; Gao, H.; Vali, H.; Kennedy, D. W.; Yang, Z. K.; Gao, W.; Dohnalkova, A. C.; Stapleton, R. D.; Moon, J. W.; Phelps, T. J.; Fredrickson, J. K.; Zhou, J. Appl. Environ. Microbiol. 2006, 72, 3236-3244.

(19) Zachara, J. M.; Kukkadapu, R. K.; Fredrickson, J. K.; Gorby, Y. A.; Smith, S. C. Geomicrobiol. J. 2002, 19, 179-207.

(20) Zhang, C. L.; Liu, S.; Phelps, T. J.; Cole, D. R.; Horita, J.; Fortier, S. M.; Elless, M.; Valley, J. W. Geochim. Cosmochim. Acta. 1997, 61, 4621-4632.

(21) Perez-Gonzalez, T.; Jimenez-Lopez, C.; Neal, A. L.; Rull-Perez, F.; RodriguezNavarro, A.; Fernandez-Vivas, A.; Iañez-Pareja, E.; Geochim. Et Cosmochim. Acta. 2010, 74, 967-979.

(22) Martín, M.; Carmona, F.; Cuesta, R.; Rondón, D.; Gálvez, N.; Domínguez-Vera, J. M. Adv. Funct. Mater. 2014, DOI: 10.1002/adfm. 201303754.

(23) Cheon, J.; Lee, J. H. Acc. Chem. Res. 2008, 41, 1630-1640. (24) Dobson, J. Nat. Nanotech. 2008, 3, 139-143.

(25) Mornet, S.; Vasseur, S.; Grasset, F.; Duguet, E. J. Mater. Chem. 2004 14, 21612175 .

(26) Laurent, S.; Forge, D.; Port, M.; Roch, A.; Robic, C.; Elst, L. V. Chem. Rev. 2008, $108,2064-2110$.

(27) Daniel, M. C.; Astruc, D. Chem. Rev. 2004, 104, 293.

(28) Pastoriza-Santos, I.; Liz-Marzan, L. M. Meth. Mol. Biol. 2013, 1025, 75-93.

(29) Lim, J. K.; Majetich, S. A. Nano Today. 2013, 8, 98-113.

(30) Dreaden, E. C.; Alkilany, A. M.; Huang, X.; Murphy, C. J.; El- Sayed, M. A. Chem. Soc. Rev. 2012, 41, 2740-2779.

(31) Wang, L.; Park, H. Y.; Lim, S. I.; Schadt, M. J.; Mott, D.; Luo, J.; Wang, X.; Zhong, C. J. J. Mater. Chem. 2008, 18, 2629-2635.

(32) Salgueiriño-Maceira, V.; Correa-Duarte, M. A.; Farle, M.; Lopez-Quintela, A.; Sieradzki, K.; Diaz, R. Chem. Mater. 2006, 18, 2701.

(33) Correa-Duarte, M. A.; Salgueiriño-Maceira, V.; Rodriguez-Gonzalez, B.; LizMarzan, L. M.; Kosiorek, A.; Kandulski, W.; Giersig, M. Adv. Mater. 2005, 17, 2014. 
(34) Liu, H. L.; Wub, J. H.; Min, J. H.; Kim, Y. K. J. of Alloys and Compounds. 2012, $537,60-64$.

(35) Spasova, M.; Salgueirino-Maceira, V.; Schlachter, A.; Hilgendorff, M.; Giersig, M.; Liz-Marzan, L. M.; Farle, M. J. Mater. Chem. 2005, 15, 2095-2098.

(36) Liquid cultures of Lactobacillus fermentum ${ }^{\circledR}$ were grown in MRS broth (Panreac, 413785) at $37{ }^{\circ} \mathrm{C}$ with orbital agitation for $24 \mathrm{~h}$ until early stationary phase. Bacteria were then collected via centrifugation and resuspended in Hank's Balanced Salt Solution to a final concentration of $1 \mathrm{mg} / \mathrm{mL}(3.5 \times 108 \mathrm{CFU} / \mathrm{mL})$. An $\mathrm{Au}(\mathrm{III})$ aqueous solution (Gold tetrachloride, Sigma-Aldrich, 99\%), was dissolved in Type 1 Milli-Q ultrapure water and then added to the bacterial suspension to give a final concentration of $1 \mathrm{mM}$. The reaction mixture was kept at $37^{\circ} \mathrm{C}$ and under continuous stirring for $30 \mathrm{~min}$. until the appearance of a characteristic redwine colored solution, indicating the formation of gold nanoparticles. The resulting gold-biomass was centrifuged at $100 \mathrm{rpm}$ for $30 \mathrm{~min}$. The supernatant exhibited no band in the visible region. The quantity of gold measured by inducively coupled plasma mass spectrometry was zero. Control reactions in the absence of Lactobacillus fermentum ${ }^{\circledR}$, where the culture supernatants of Hank's Balanced Salt Solution and MRS broth both exhibited no color change or absorbance at $520 \mathrm{~nm}$, clearly indicated that the presence of bacteria in the biosynthesis of gold nanoparticles is a prerequisite. An acidic solution $(\mathrm{pH} 2)$ of maghemite nanoparticles ( $1 \mu \mathrm{L}$, at 0.95 - $1 \mathrm{M}$ of iron), prepared as previously reported, ${ }^{39}$ was added to the gold-loaded Lactobacillus fermentum ${ }^{\circledR}$ and maintained at $37{ }^{\circ} \mathrm{C}$ under orbital agitation for $30 \mathrm{~min}$. The reaction mixture was washed with several centrifugation cycles (100 rpm, $5{ }^{\circ} \mathrm{C}, 30$ minutes), to remove any unbound maghemite nanoparticles, and the final bacterial pellet resuspended in a $50 \mathrm{mM}$ sodium citrate, PBS, Milli-Q water 1:1:4 mixture at $\mathrm{pH}$ 5. The resulting gold+maghemite-Lactobacillus fermentum ${ }^{\circledR}$ suspension remained stable at room temperature.

(37) The sample of gold+maghemite-Lactobacillus fermentum ${ }^{\circledR}$ was embedded in an epoxy resin. Fixation was achieved by adding $2.5 \%$ glutaraldehyde in a $0.1 \mathrm{M}$ sodium cacodylate buffer solution at $4 \stackrel{\circ}{ } \mathrm{C}$ for $4 \mathrm{~h}$. The sample was washed three times in $0.1 \mathrm{M}$ sodium cacodylate buffer for 15 minutes. Then, drying cicles with ethanol and propylene oxide were applied. Finally, the sample was embedded in an 
epoxy resin and left overnight at $4{ }^{\circ} \mathrm{C}$. After ultramicro-cutting, samples were observed with a FEI TITAN G2 microscope.

(38) Valero, E.; Tambalo, S.; Marzola, P.; Ortega-Muñoz, M.; Lopez-Jaramillo, J.; Santoyo, F.; Lopez, J. D.; Delgado, J. J.; Calvino, J. J.; Cuesta, R.; Dominguez-Vera, J. M.; Gálvez, N. J. Am. Chem. Soc. 2011, 133, 4889.

(39) Park, J.; Lee, E.; Hwang, N. M.; Kang, M.; Kim, S. C.; Hwang, Y.; Park, J. G.; Noh, H-J.; Kim, J-Y.; Park, J-H.; Hyeon, T. Angew. Chem. Int. Ed. 2005, 44, 2872.

(40) Quantification of bacteria proliferation was performed by using the Live/Dead Bacterial Viability Kits SYT09 (green) and Propidium Iodine (red) (Invitrogen), counting the number of live (green) and dead (red) bacteria in a batch of three experiments by the software Image-Pro Plus 6.0. The average live/dead ratio was used to quantify the bacteria proliferation by comparing with control experiments where no nanoparticles were present. The presence of maghemite and gold nanoparticles resulted in a decrease of the live/dead ratio of $15-25 \%$ for three independent experiments carried out in Hank's Balanced Salt Solution (Figure SI). 